\title{
Tonic, phasic and cortical arousal in Gilles de la Tourette's syndrome
}

\author{
RICHARD D BOCK, LEO GOLDBERGER \\ From the Department of Psychology, New York University, New York, USA
}

SUMMARY This study explored the hypothesis that Gilles de la Tourette's syndrome involves a disturbance in arousal modulation. The experimental group consisted of 20 unmedicated subjects with the Gilles de la Tourette's syndrome, and the control group of 20 subjects with chronic medical illnesses (haemophilia, von Willebrandt's disease and diabetes). There were differences between groups in the manner in which log conductance level changed over time during sound and light habituation experiments involving mild levels of stimulation with the Gilles de la Tourette group showing less change in arousal level over trials than the control group. No group differences were found in measures of phasic arousal, rate of spontaneous fluctuations and performance on two tasks that have been related to cortical arousal. It is suggested that the slower change in log conductance level in the Gilles de la Tourette group during the sound and light habituation experiments indicates that reticular activity is more persistent in these patients.

Gilles de la Tourette's syndrome is a disease characterised by multiple involuntary muscular tics and vocalisations which may be accompanied by one or more of several symptoms: coprolalia, echolalia, palilalia, and echokinesis. ${ }^{2}$ Age of onset varies between two and 15 years; the mean age of onset in the most extensive study of Gilles de la Tourette patients is seven years. ${ }^{2}$ Once the symptoms are established, they wax and wane. Until recently, the syndrome was considered to be a movement disorder of unknown origin with most studies focused on the role of psychopathological and organic factors in the disorder. As clinical studies have found evidence of difficulties which extend beyond the motor sphere in some Gilles de la Tourette patients, including problems in control of aggressive, sexual and selfdestructive impulses, ${ }^{2-5}$ difficulties in the regulation of attention and emotional responses, ${ }^{4}$ sleep disturbances $^{35}$ and difficulties in autonomic control, ${ }^{3}$ the syndrome has been redefined by some investigators as a more generalised disturbance of inhibitory controls of the central nervous system. ${ }^{4}$

Our study explored the hypothesis that a distur-

Address for reprint requests: Leo Goldberger, PhD, Dept of Psychology, New York University, 6 Washington Place, 4th floor, New York, NY 10003, USA.

Received 17 February 1984 and in revised form 31 July 1984 Accepted 6 August 1984 bance in arousal is an integral aspect of the Gilles de la Tourette syndrome. This hypothesis was developed by clinicians actively engaged in the treatment of Gilles de la Tourette patients. ${ }^{4-10}$

Clinical discussions of this issue have suggested that the arousal dysfunction involves a disruption of arousal modulation ${ }^{8}$ and of inhibition. ${ }^{4-10}$ As Turpin $^{410}$ has noted, several of the researchers who postulate a disruption of inhibition have suggested that tics are exaggerated and poorly controlled starthe responses. ${ }^{6-7}$ This study explored both the disruption in arousal modulation and inhibition hypotheses. The first would create greater variability on measures of arousal while the second could be caused by either excessively high or excessively low levels of arousal. The optimal level of arousal for a wide range of psychological functions is a moderate one. ${ }^{11} 12$ This study also explored the influence of the arousal-related personality variables extraversion and neuroticism. Findings from this part of the study will be described in another paper. Because of the dissociation of arousal systems, ${ }^{13}$ this study included measures of several systems: tonic and phasic autonomic arousal and cortical arousal.

Operationally, the basal skin conductance level $^{14}$ is and the rate of spontaneous fluctuations ${ }^{14}$ were the measures of tonic autonomic arousal. Amplitude of the skin conductance response and rate of habituation measured phasic autonomic 535 
arousal. ${ }^{17}{ }^{18}$ Cortical arousal was assessed indirectly by the Continuous Performance Test (CPT) ${ }^{14}$ and the Stroop Color-Word test. A variety of studies have demonstrated that CPT performance is affected by changes in cortical arousal..$^{20-23}$ Use of the Stroop as an index of cortical arousal was based on the idea that the task demanded efficient cortical functioning for successful performance. Klein's discussion of the variety of mental operations demanded by the task suggested the need for such efficiency. ${ }^{24}$ Studies using a variety of manipulations, including administration of amphetamine and amobarbitol, ${ }^{25}$ exposure to loud noise, ${ }^{26}$ threat of shock,${ }^{27}$ and varying the length of time that a subject has to respond to a stimulus ${ }^{28}$ have demonstrated that performance on the Stroop is effected by more general shifts in arousal.

For all electrodermal variables, the study explored both the disruption of arousal modulation and inhibition hypotheses. This aspect of the study was the most exploratory. At the time the study was conducted, the only prior work on electrodermal arousal in the Gilles de la Tourette syndrome was a pilot study that found a relationship between the occurrence of motor tics and galvanic skin response in a single patient with Gilles de la Tourette syndrome and another with motor tics (Corbett JA, Tics in Childhood. Unpublished MS 1967). Clinical reports of blocking and attention disturbances ${ }^{4}$ suggested that the problem of inhibition was central in relation to cortical arousal. Consequently for both the CPT and the Stroop tests, only the inhibition hypothesis was explored.

Methods

\section{Subjects}

Experimental Individuals with Gilles de la Tourette syndrome were recruited with the assistance of the Tourette Syndrome Association, a self-help group of patients and parents. A mailing describing the research project was sent to 1,000 members of the Association in New York, New Jersey and Connecticut. The mailing was accompanied by a letter explaining the project that was signed by officers of the Association. Over 75 people responded to this mailing, most of whom were being treated with medications such as haloperidol and clonidine that affect the arousal system. Twenty of these people were not on arousal-related medications; 17 took part in the study, but mechanical difficulties interfered with the recording of physiological responses in one. An additional four subjects who were not being treated with arousal-related medications were recruited through personal contacts of the researcher. (The Tourette syndrome questionnaire developed by the Tourette and Tic Laboratory at Mt. Sinai Medical, New York City, was administered to all experimental subjects to confirm the Gilles de la Tourette diagnosis. This questionnaire inquires about a variety of symptoms and establishes the age of the onset and duration of each symptom.
Responses from the questionnaire were scored for the three basic symptoms of the disorder: multiple muscular and vocal tics and waxing and waning course of symptoms. ${ }^{2}$ A history of these three basic symptoms was considered to be confirmation of diagnosis. In two cases where questionnaire responses did not establish the diagnosis, observational evidence of symptoms was used to supplement the basic data.)

Control This study required a control group of subjects with chronic medical illnesses to control for the possibility that the arousal disturbance symptoms noted in people with Gilles de la Tourette's syndrome might be a reaction to the chronic, unpredictable nature of the syndrome. A number of chronic medical illnesses, such as asthma, endocrine disorders, and epilepsy are treated with medications that affect the arousal system, which would have introduced a confounding variable. The control group for this study was made up of subjects with haemophilia, von Willebrandt's disease (vascular haemophilia) and diabetes, chronic medical illnesses which are not treated with medications that affect the arousal system.

Control subjects with either haemophilia, von Willebrandt's disease or diabetes were recruited with the assistance of several self-help groups, hospital clinics and private physicians. The self-help groups were the Metropoli$\tan$ New York Chapter of the Hemophilia Foundation and a voluntary discussion group for diabetics conducted at the New York University Medical Center. The Department of Pediatric Hematology and the High Risk Program for Diabetes, both of New York Hospital, were the cooperating clinics. All controls were first contacted about the study either by someone involved in their medical treatment or by a member of their organisation. They were told that this was a study of Gilles de la Tourette's syndrome and those who were not familiar with the condition were informed of its symptoms. People who expressed an interest in participating were curious about why their condition had been selected, and the reason for this choice (the fact that their illness shared an element of unpredictability with the Gilles de la Tourette syndrome) was explained. Transportation expenses were provided for all control subjects.

Matching An equal number of male and female subjects were recruited in the Gilles de la Tourette and the control group. Precise matching for age was not possible. Instead, subjects were recruited in such a way that no major difference in age existed between the two groups. The mean age of the Gilles de la Tourette group was 27.3 years $(\mathrm{SD}=$ 14.91; Minimum $=10$; Maximum $=62$ ). The mean age of the control group was 26.9 years $(S D=12.04$; Minimum $=9$; Maximum $=52$ ). The mean age for males in the Gilles de la Tourette group was 30.7 (SD = 18.07; Minimum $=10 ;$ Maximum $=62$ ) and for females, 23.9 $(S D=10 \cdot 81$; Minimum $=11$; Maximum $=45)$. Comparable figures for the control subjects were: Mean age for males, 28.2 years $(S D=14 \cdot 89$; Minimum $=9$; Maximum $=52)$; Mean age for females, 25.7 years $(S D=8.96$; Minimum $=9$; Maximum $=38$ ). There were no significant differences between the Gilles de la Tourette and control subjects on the age variable, either for the groups as a whole, $t(38)=0.08, \mathrm{p}>0.05$, or for the male or female 
subgroups (for males, $t(18)=0.337, \mathrm{p}>0.05$; for females $t(18)=-0.405, \mathrm{p}>0.05)$.

Apparatus Subjects were tested in a sound-proof, temperature-controlled room at the Research Center for Mental Health, New York University. Temperature was kept at approximately $70^{\circ} \mathrm{F}$ for all subjects. The Continuous Performance Test was constructed by the Psychological Workshop at New York University according to specifications outlined in the original article describing the test $^{22}$ with some modifications. The test was constructed with a memory drum and the timing system with a Hunter $120 \mathrm{~A}$ Klockounter and relays. This version of the CPT presented stimuli at a frequency of one-per-second and stimuli were illuminated for this period of time as well. Prior versions have presented the stimuli at the same speed, but illumination of the stimulus has been shorter (for example $0 \cdot 1 \mathrm{~s}$ ). Basal skin resistance levels and phasic skin resistance responses to sound and light stimuli were recorded by a Beckman Type RM Dynagraph, using a Beckman 9892A skin resistance coupler. A constant current of 0.5 microamps was administered to subjects across two standard size Beckman silver-silver chloride electrodes. These electrodes were attached by adhesive collars. The skin of all subjects was cleansed with alcohol prior to electrode placement. The electrolyte medium was a commercial preparation, KY Jelly. The auditory stimulus for the habituation experiment was a $450 \mathrm{~Hz}$ tone presented to both ears through earphones at $65 \mathrm{~dB}$. The visual stimulus was a small 5-watt bulb with a white plastic cover. Stimuli for the Stroop were constructed according to models of the test used in previous work at New York University. ${ }^{24}$

\section{Procedures}

The following procedures were used for all subjects. Introduction During this period, tester and observer were introduced to the subject in an informal manner. A brief summary of the procedures was presented and the purpose of the testing (to help gain a better understanding of the Gilles de la Tourette syndrome) was described. After appropriate questions were answered, experimenter, observer and subject all went into the experimental room.

\section{Testing}

Tests were presented in a fixed order to all subjects: (1) Continuous Performance Test, (2) Habituation-sound, (3) Habituation-light, and (4) Color-word test. A fixed order was used because of the anticipated small sample size as well as to allow the experimenter to focus on individual differences. On the CPT, subjects were presented with two tasks. In both of these tasks, a series of letters was presented one at a time in a small window that was in front of the memory drum. For the first task, the subject was instructed to press a response key whenever an $X$ appeared in the window. For the second task, the subject was instructed to press the key every time an $X$ appeared after it had been preceded by an A. A response was scored correct if the subject pressed the response key within 0.69 seconds after the illumination of the correct letter. This figure was used according to instructions found in the initial article describing the test. ${ }^{19}$ Correct and incorrect responses were recorded by an experimenter who was sea- ted directly across from the subject behind a set of relays and a timing device. All subject responses triggered a red light which allowed the experimenter to identify correct as well as incorrect responses. The $\mathrm{X}$ task included a number of randomly-selected letters from the alphabet as well as eight Xs. All letters were presented one at a time in the viewing window. After a brief practice period, subjects were given a 10 minute test in which there were approximately 50 correct responses (the number varied slightly because of occasional mistrials). A brief practice period preceded both the $X$ and the $A-X$ task. In the A-X task. there were five correct responses embedded in a series of 31 letters.

After completion of the CPT, subjects were instructed to sit in a large, cushioned chair. They were told that the experiment would take approximately 45 minutes and that there would be nothing painful or unpleasant about it. Electrodes were then attached to the proximal phalanx of the index or middle fingers of the left hand; a ground electrode was also attached to the person's left arm. Several of the subjects had calluses at this site, and for these, a palm placement was used. Once electrodes were attached, a 15 minute interval preceded the recording session. After this period, the subject was instructed to sit quietly and listen to sounds that came through the earphones. The subject was also instructed to try not to move the arm on which the electrodes were attached. Both auditory and visual stimuli were presented for one second, 20-30 times over a 10 minute interval. The interstimulus interval for all stimuli was $25 \mathrm{~s}$, which was slightly longer than the standard ISI found in a number of habituation experiments reviewed in the literature. This lengthened ISI was used to allow for the possibility, suggested by the hypothesis, that some Gilles de la Tourette subjects might have atypical responses. The light for the visual stimulus was placed before the subject on a table approximately one yard in front of where he was sitting. During presentation of the visual stimulus, lighting in the room was reduced to $3.425 \mathrm{~cd} / \mathrm{m}^{2}$.

Once the sound series of the habituation experiment was completed, the earphones were removed and the light stimulus put into position. The subject was then told to keep his/her eyes on the light, which would flash on or off. A short break followed the administration of the visual habituation experiment.

The Stroop test consisted of three separate tasks. On the first task, the subject had to read 10 lines of colour names printed in black ink. On the second task, the subject had to identify the colours of 10 lines of groups of asterisks printed in blue, green, orange and red inks. On the final task, the subject had to identify the colours of colourwords printed in incongruous colours (for example, if the word blue was printed in red, the subject had to say the colour red and inhibit the word). Reading times and reading errors on all tasks were noted by the experimenter at the time of testing. In addition, the subject's respose was taped and responses were scored a second time after the testing. Discrepancies between on-line and taped versions of the Stroop were decided in favour of the taped version.

After administration of all tests the purpose of the experiment was explained to subjects.

Two people were always involved during administration of the CPT, the habituation experiment and the Color- 
Word test. For the CPT, one person was sitting across from the subject, as described above, while the second was seated across the room, slightly to the rear of the subject. For the Gilles de la Tourette group, this person was involved in rating symptomatology using the tic rating scale. In order to control for the effect of observer presence on arousal variables, a second person was also seated in the room during administration of test procedures to control subjects. During these sessions, the observer made notes about the subject's alertness. The second person was always introduced to subjects as someone who would help to "keep score."

During the habituation experiment, one person was always seated in front of the subject, while a second person was outside the room running the dynagraph. The observer in the room noted the occurrence of movements of the left arm or hand that could produce movement artifact during presentation of the sound and light stimuli and also noted whether the subject kept his eyes on the light during the second experiment. Several observers had difficulty with the latter task because the room was dim. For the Stroop test, the second person sat behind the subject again and made the same ratings as during the CPT.

\section{Scoring}

On the CPT, the $X$ and $A-X$ responses of each subject were scored in absolute as well as in relative terms. ${ }^{19}$ The absolute score consisted of the number of correct responses that the subject had made, divided by the number of correct responses possible in the time allowed. The relative score was defined as the number of correct responses made divided by the number of attempts, both correct and incorrect, during the time allowed. Both scores were reported in percentage terms.

Since a constant current system was used, all electrodermal variables were initially recorded in resistance units. Samples of the basal skin resistance level were measured immediately before the onset of stimuli 1, 5, 10,15 and 20 in both the sound and light series. ${ }^{30}$ Any decrease in skin resistance that exceeded 400 ohms $^{173031}$ which began within one-to-three s after stimulus onset ${ }^{32}$ was scored as a skin resistance response. The peak of the wave reached within up to five $s$ after the initial drop in resistance level was scored as the amplitude of the response. ${ }^{33}$ In those few instances in which the wave was still ascending to peak after five s, this limit was extended. All responses of 400 ohms or more that occurred outside the latency limits were scored as spontaneous fluctuations (SF). All responses were hand-scored with a ruler by one rater and checked by a second.

A standard criterion of three consecutive nonresponses ${ }^{17} 3435$ was used to determine the point at which a subject habituated to a stimulus.

Trials involving electrodermal variables that had to be eliminated because of movement artifact or recording difficulties were not included in the data analysis. When trials were eliminated, mean variances and other stastistics were calculated on the basis of the trials that remained. If the elimination of a trial interfered with the calculation of a trials to habituation criterion, that subject was dropped from the data analysis.

Prior to statistical analysis, electrodermal variables were converted into conductance units in order to meet current standards. $^{34}$ Scores were then normalised with a logarithmic transformation in order to minimise the contribution of extreme values. Following this transformation, several new variables were created.

From tonic level scores seven dependent variables were generated for each habituation series. The first five were simply the transformed tonic level readings at the five points sampled originally. The final two were created on the basis of a regression analysis in which the five tonic level values were regressed on trials. The first of these was a slope value, the second an $\mathrm{R}$-squared value. The last two values were added after preliminary plotting of tonic level values suggested that control subjects experienced a steeper and more even decrease in skin conductance than Gilles de la Tourette subjects. A steady decrease in skin conductance (a decline in arousal) is the normal reaction of subjects to this experimental procedure (Bernstein, personal communication).

There is considerable controversy about whether the law of initial value, which states that response amplitude of autonomic measures is inversely related to pre-stimulus level, applies to electrodermal measures. ${ }^{32}{ }^{37}$ One study reviewed here indicated that some individuals are more subject to the law than others. ${ }^{37}$ In the present study, an empirical approach was used: the significance of the correlation between response amplitude and pre-stimulus level for the first response of each series was tested. ${ }^{31}{ }^{38}$ Subsequent responses were not used because of anticipated habituation effects. This approach found a significant negative correlation between log conductance change and log conductance level (measured when the response began) in relation to the first trial of the sound series, $r(30)=$ $-0.539, p<0.01$, and a non significant correlation between the two variables for the first trial of the light series, $r$ (24) $=-0 \cdot 138, p>0 \cdot 05$. There were no significant differences between the two groups in the correlation between log conductance change values and conductance level values for either the sound or the light series (Fisher's $z$ ', Normal $Z$ value, Sound $=0.339$, Light $=0.808$ )

On the basis of this analysis, the log conductance change values from the first response of the sound series were transformed into autonomic lability scores. ${ }^{39}$ This procedure provides a correction for the influence of basal values on change scores and normalises the scores with a mean of 50 and a standard deviation of 10 . For the first trial of the light series, the log conductance change score was used rather than the autonomic lability score.

Since prior studies with the Stroop test have found a positive correlation between reading time on the colours alone condition and reading time on the colour-word condition, analysis of co-variance was used to correct for the effect of colour-coding time on the second task. Covariance analysis was also used to correct for the influence of colour-coding on errors in colour-word naming.

The Tourette and Tic Laboratory Rating Scale (Shapiro and Shapiro, unpublished rating scale) was used to monitor Gilles de la Tourette movements during the Continuous Performance Test and the Stroop Color-Word test. This scale rates Gilles de la Tourette symptoms as absent, mild, moderate, marked, or very severe according to the following criteria: 
0 = Absent: no symptoms in five minute period;

1 = Mild: 1 symptom per minute or $1-5$ per five minute period;

$2=$ Moderate: 2-5 symptoms per minute or 6-25 per five minute period;

$3=$ Marked: $6-10$ symptoms per minute or $26-50$ per five minute period;

4 = Very severe: over 10 symptoms per minute or more than 51 per five minute period.

During the habituation experiment, raters used a prepared rating sheet to note trials on which movement interfered with accurate recording of electrodermal activity in both Gilles de la Tourette and control subjects.

\section{Statistical tests}

Hierarchical multiple regression analysis was used to test all hypotheses. ${ }^{40}$ Hierarchical analysis is the equivalent of repeated analyses of covariance. At each stage, prior variables have been partialled out and the variable that is entered last in the multiple regression equation is the research factor of interest. In hierarchical analysis, variables are added to the regression equation in a fixed order. At each step of the analysis, an increment value, the squared semi-partial correlation co-efficient is computed for the variable of interest. The statistical significance of this value is determined by the F-test. The nature of the multiple regression equation used in each statistical test varied somewhat based on the relevance of the independent variables to the dependent variable. For all tests, group membership was coded by means of dummyvariable coding and age was entered into the multiple regression equation as a co-variate. In instances in which elimination of subjects resulted in an unequal distribution of male and female subjects in each group, sex was entered into the equation prior to age as a co-variate. Homogeneity of regression of co-variates was tested by the $t$ test of differences between regression co-efficients.

The influence of severity of Gilles de la Tourette symptoms on CPT and Stroop test peformance was tested by an additional regression equation. For Stroop scores, colourcoding was added to the equation prior to the severity variable. For CPT scores, no other variables were added.

For dependent variables for which greater variance in the Gilles de la Tourette group was predicted, absolute within-group deviation scores were used to test the hypothesis. ${ }^{445}$

Results

\section{AUTONOMIC AROUSAL-TONIC}

Log conductance level

When log conductance level values sampled at five points during the sound and light habituation experiments were regressed on trials, the amounts of variance accounted for by the regression line was significantly greater in control subjects than in Gilles de la Tourette subjects (see tables 1 and 2). Furthermore, the average slopes of the regression lines of the groups differed significantly in the sound habituation experiment and approached significance in the
Table 1 Group differences in amount of variance accounted for by the regression line when tonic level values are regressed on trials

\begin{tabular}{lcll}
\hline \multicolumn{2}{l}{ Sound habituation series } & & \\
$I V$ & $S R^{2}$ & $F$ & $d f$ \\
Age & $0 \cdot 002$ & $0 \cdot 11$ & 1,38 \\
Group & 0.215 & $11 \cdot 93^{*}$ & 1,37 \\
Light habituation & series & & \\
$I V$ & $S R^{2}$ & $F$ & $d f$ \\
Age & 0.126 & $7 \cdot 10 \dagger$ & 1,38 \\
Group & 0.099 & $5 \cdot 63 \ddagger$ & 1,37 \\
\hline
\end{tabular}

For Sound, if Alpha $=0.05$, power $>0.80$

For Light, if Alpha $=0.05$, power $>0.50$

$* p<0.002$

tp $<0.01$

$\neq \mathrm{p}<0.02$

light habituation experiment (see tables 3 and 4). In both cases, the slopes of the Gilles de la Tourette subjects were flatter.

In order to further understand these results, a repeated measure analysis of variance was performed, using log conductance level values sampled from the point of stimulus onset for all 22 trials for each subject. The results of this analysis are shown in tables 5 and 6 and figures 1 and 2 . The form of the significant group $\times$ trials interaction effect found in the repeated measures analysis indicates that the Gilles de la Tourette subjects experienced less change in arousal level than controls during the habituation experiments.

There were no significant differences between the Gilles de la Tourette and the control groups on the heterogeneity of variance measure for tonic variables.

\section{Spontaneous fuctuations}

There were no statistically significant differences in the rate of spontaneous fluctuations between groups in either of the habituation experiments. However, there was a trend in both experiments for the Gilles de la Tourette group to have a higher rate of spontaneous fluctuations than controls. During the sound habituation experiment, the mean number of spon-

Table 2 Mean values for the amount of variance accounted for by the regression line when tonic level values are regressed on trials

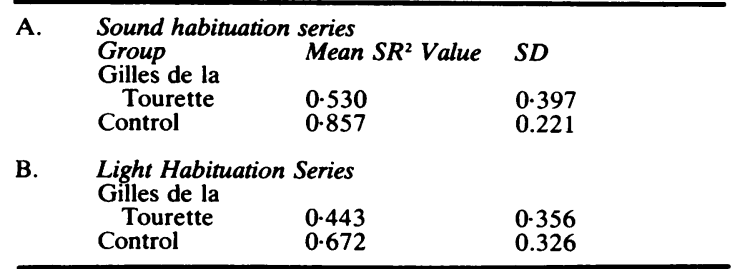


Table 3 Group differences in value of the regression coefficient for regression of tonic level values on trials

\begin{tabular}{|c|c|c|c|}
\hline \multicolumn{4}{|c|}{ Sound habituation series } \\
\hline IV & $S R^{2}$ & $F$ & $d f$ \\
\hline Age & 0.0002 & 0.01 & 1,38 \\
\hline Group & 0.276 & $12 \cdot 09^{*}$ & 1,37 \\
\hline \multicolumn{4}{|c|}{ Light habituation series } \\
\hline Age & 0.060 & 2.96 & af \\
\hline Group & 0.075 & $3.68 \dagger$ & 1,37 \\
\hline
\end{tabular}

For Sound, if Alpha $=0.05$, power $>0.95$

For Light, if Alpha $=0.05$, power $<0.50$

*p $<0.001$

$+\mathrm{p}<0.06$

taneous fluctuations per trial for the Gilles de la Tourette group was $1 \cdot 12$, for controls, $0 \cdot 67(F 1,37$ $=2.67, \mathrm{p}<0.12)$. During the light habituation experiment the mean number of spontaneous fluctuations per trial for the Gilles de la Tourette group was $1 \cdot 29$, for controls, $0 \cdot 82(F 1,37=2 \cdot 88$, p $<0 \cdot 10)$. There were no statistically significant differences between groups on the heterogeneity of variance measure for spontaneous fluctuations in either the sound or light experiment.

\section{AUTONOMIC AROUSAL-PHASIC}

Analyses of phasic variables were conducted with fewer subjects than those of other variables because of the elimination of subjects. There were two reasons for elimination: non-responsiveness of subjects and recording difficulties. There were no significant differences between groups in the incidence of non-responsiveness or recording difficulties.

There were no significant differences between groups on measures of phasic arousal. Group differences approached significance on only one phasic variable, the autonomic lability score (ALS) for the first stimulus of the sound experiment $(F(1,28)=$ $3.78, p<0 \cdot 07)$. On this variable, mean ALS of the Gilles de la Tourette group (54.65) was smaller than mean ALS of the control group (55.98). There were also no significant differences on any of the phasic heterogeneity of variance measures.

\section{CORTICAL AROUSAL}

Continuous Performance Test (CPT)

There were no significant group differences on any

Table 4 Mean tonic level slope values-Gilles de la Tourette and control subjects

\begin{tabular}{lll}
\hline Sound habituation series & \\
Group & Mean Slope Value & SD \\
Tourette & -0.011 & 0.012 \\
Control & -0.038 & 0.031 \\
Light habituation series & \\
Group & Mean Slope Value & SD \\
Tourette & -0.009 & 0.015 \\
Control & -0.020 & 0.022 \\
\hline
\end{tabular}

Table 5 Repeated measures analysis of variance for log conductance level values-sound habituation experiment

\begin{tabular}{lrrlr}
\hline Source & \multicolumn{1}{c}{ SS } & \multicolumn{1}{c}{$d f$} & MS & \multicolumn{1}{c}{ F-Test } \\
Group & 2.42 & 1 & 2.42 & 0.836 \\
Error & 109.98 & 38 & $2 \cdot 89$ & \\
Trials & 0.93 & 21 & 0.04 & $27 \cdot 240^{*}$ \\
Group $\times$ Trials & 0.33 & 21 & 0.02 & $9.753^{*}$ \\
Error & 1.17 & 719 & 0.002 & \\
Total & 114.82 & 800 & & \\
\hline
\end{tabular}

* $p<0.001$

of the CPT variables.

\section{Stroop Color-Word test}

There were no significant group differences on either of the colour-word variables-reading time on the colour-word condition and errors made while reading the page of words printed in incongruous colours.

\section{Severity of symptomatology}

On the CPT, Gilles de la Tourette subjects experienced moderate symptoms during both the $X$ and the A-X tasks. Symptoms were mild on the Stroop test (see table 7). There was a significant decrease in the incidence of tic symptoms between the final CPT condition (CPT-A-X) and the first Stroop condition (Words alone), $t(38)=3.55, \mathrm{p}<0.01$.

Severity of symptomatology did not significantly influence scores on any of the six tasks for which it was measured.

\section{Discussion}

The findings of this study suggest that clinical discussions concerning the role of arousal in Gilles de la Tourette's syndrome have been too broad. These discussions have used arousal as a general concept that relates to the activity of the nervous system as a whole and have not taken into account the dissociation of arousal systems. ${ }^{13}$ This study found no evidence in Gilles de la Tourette patients for arousal disturbances hypothesised by clinicians on performance tasks that have been related to cortical arousal or in amplitude or habituation rate of phasic electrodermal responses. Researchers using more

Table 6 Repeated measures analysis of variance for log conductance level values-light habituation experiment

\begin{tabular}{lrrlr}
\hline Source & \multicolumn{1}{c}{$S S$} & \multicolumn{1}{l}{$d f$} & $M S$ & F-Test \\
Group & 1.52 & 1 & 1.52 & 0.550 \\
Error & 105.07 & 38 & 2.77 & \\
Trials & 0.42 & 21 & 0.02 & $12.45^{*}$ \\
Group $\times$ Trials & 0.08 & 21 & 0.004 & $2.22 \dagger$ \\
Error & 1.16 & 718 & 0.002 & \\
Total & 108.25 & 799 & & \\
\hline${ }^{*} \mathrm{p}<0.001$ & & & & \\
$\dagger p<0.002$ & & & &
\end{tabular}


Table 7 Ratings of severity of symptomatology by task

\begin{tabular}{lcc}
\hline Task & Mean & $S D$ \\
Continuous Performance & Test & \\
X & $2 \cdot 1$ & 1.38 \\
A-X & $2 \cdot 2$ & 1.40 \\
Stroop Color-Word Test & & \\
Words Alone & 0.75 & 1.37 \\
Colors Alone & 0.90 & 1.55 \\
Color-Word & 0.75 & 1.25 \\
\hline
\end{tabular}

direct measures of cortical arousal such as the electroencephalogram ${ }^{2}$ and evoked potential studies $^{43}$ also report no characteristic dysfunction in Gilles de la Tourette patients. In addition, a recently conducted study that included electrodermal measures of habituation of responses to click stimuli found no disturbance in the habituation process in Gilles de la Tourette patients. ${ }^{10}$ This study notes that the failure to find a disturbance in the habituation process in Gilles de la Tourette patients challenges the idea that the syndrome involves a disturbance in inhibition of the startle reflex. Such a disturbance would be accompanied by higher levels of reactivity and delayed habituation to sensory stimulation.

The major finding of this study was that Gilles de la Tourette's syndrome subjects experienced less change in tonic arousal level over time than controls during the sound and light habituation experiments. There are several possible interpretations of this finding. The first is that the Gilles de la Tourette group may have been more motivated to remain alert during the habituation trials. As noted above, decrease in skin conductance level with stimulus repetition is the norm in habituation experiments. Such a decrease can be an indication of boredom on the part of test subjects in response to the repetitive

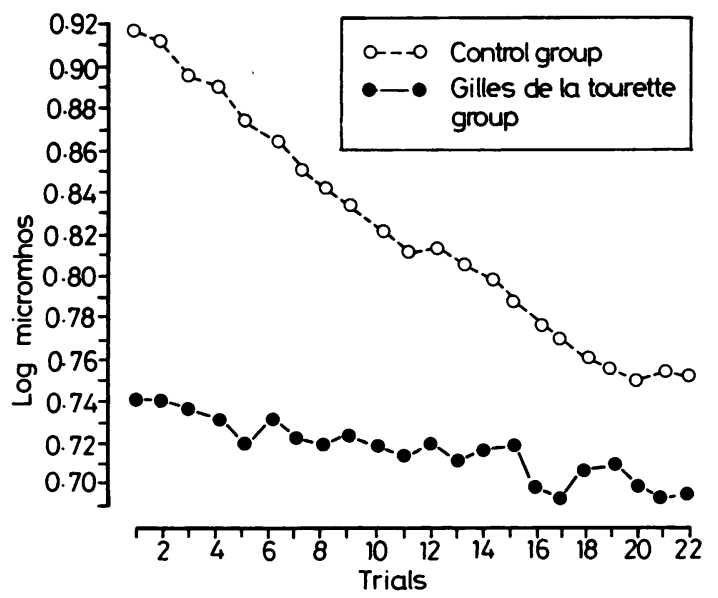

Fig 1 Mean log conductance level for each group by trials (sound)

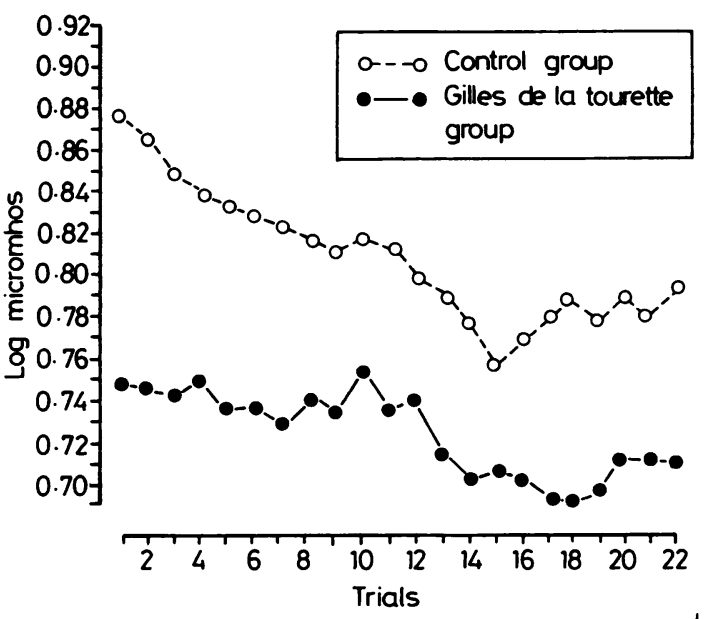

Fig 2 Log conductance level values for each group by trials (light)

nature of the stimulus. Two factors could have influenced Gilles de la Tourette subjects to succumb less readily to boredom than controls. The first is that since the Gilles de la Tourette syndrome was the focus of the study, these subjects may have made more efforts to maintain their initial level of alertness. A second factor was the presence of the observer. It is known that people with the syndrome make special efforts to hide their symptoms from others and can, with varying degrees of success, inhibit them. It is quite possible that Gilles de la Tourette subjects maintained arousal level during the habituation experiments as part of their effort to control symptoms in public. No systematic data on either of these factors was collected during the study. Consequently, no conclusions can be made concerning the manner in which they may have influenced experimental findings.

A second possible interpretation is that Gilles de la Tourette subjects experienced less change in log conductance level than controls simply because they were already functioning at lower levels of tonic arousal. In both the sound and light habituation experiments, the tonic arousal level of the Gilles de la Tourette group was consistently lower than that of controls. However, at none of the 10 points sampled during the two experiments was the difference in log conductance level between the two groups statistically significant. Consequently, it is unlikely that low levels of tonic were responsible for the experimental finding.

A third possible explanation is that the slower rate of change in log conductance level in the Gilles de la Tourette group is a consequence of physiological differences in tonic arousal between the Gilles de la 
Tourette and the control groups. Sokolov ${ }^{44}$ in his work on the orienting response, discusses tonic arousal as the background level of central nervous system activity. This form of arousal is controlled by the reticular activating system while phasic arousal involves cortical as well as reticular centres.

The slower rate of change in log conductance level experienced by the Gilles de la Tourette group during the habituation experiments suggests that reticular activity was more persistent in this group than in controls. In an experimental situation in which reticular activity normally declines sharply over time, the decline occurred more gradually in the Gilles de la Tourette group. A physiological explanation which could account for this would be that the firing rate of reticular neurons decreased more slowly in the Gilles de la Tourette group than in controls.

The trend of group differences on the second tonic level measure, spontaneous fluctuations, provides some support for this interpretation. Although differences between the two groups were not statistically significant during both the sound and light habituation experiments, the rate of spontaneous fluctuations of the Gilles de la Tourette group was consistently higher than that of the control group. The spontaneous fluctuation measure is widely regarded as an index of background activity in the central nervous system.

This persistent reticular activity interpretation of the experimental finding is speculative. However, the interpretation suggests an aetiological hypothesis for the Gilles de la Tourette syndrome that offers an explanation of the basic motor problem of the disorder and accounts for symptoms that have been noted in these patients but never included in the syndrome. The gamma efferent system, which is controlled by reticular centres, plays an important role in the regulation of muscular contraction. Persistent excitation of this system would disrupt the smooth regulation of muscle tone and lead to sudden muscular contractions. While a variety of movements accompany the syndrome, the basic symptom of the disturbance involves sudden, uncontrollable muscular contractions." Previous aetiological theories which explain the syndrome as a disturbance of motor control centres in the basal ganglia do not account for this basic symptom but focus instead on other motor symptoms that occur in some patients but are not common to all of them (for example a patient's inability to stop a normal, voluntary movement once it has been initiated).

Persistent reticular activation could also cause sleep disturbances which have been noted in clinical reports $^{35}$ as well as experimental studies. ${ }^{45} 46$ The nature of these disturbances is consistent with the persistent reticular activation model. Clinical reports describe "frequent nocturnal arousals" ${ }^{3}$ while experimental studies have recorded decreased delta sleep ${ }^{45}$ and "sudden arousals, confusion and automatisms resembling night terrors." 46

It is important to note that the sample of Gilles de la Tourette subjects recruited for this study was a special one because no member of this group was receiving medications that are commonly used in the treatment of the syndrome. The manner in which this non-medicated sample may have differed from a group of Gilles de la Tourette subjects receiving medication cannot be determined because information concerning variables that might distinguish this group from other patients (for example ratings of general syndrome severity, reaction to medication) was not collected. Ratings of symptoms made during the course of the study suggest that these subjects were from a population in which the syndrome was of mild to moderate severity. These ratings must be interpreted cautiously, however, because of the well-known ability of Gilles de la Tourette patients to inhibit symptoms in public.

The decrease in symptom severity between the final CPT trial and the first Stroop trial is a serendipitous finding. It is possible that symptoms became less severe as Gilles de la Tourette subjects became more relaxed in the experimental situation. A decrease in tic frequency with relaxation has been reported in a number of clinical studies and demonstrated experimentally as well. ${ }^{47}$ An alternative explanation is that differences in task demand between the CPT and the Stroop test caused the reduction in tic frequency. A recent experimental study and a review of case reports indicate that task demand can have an effect on tic frequency."

The authors express their gratitude to Drs. Samuel Feldman, Harold A Sackeim, Elain Shapiro and David L Wolitzky who made important contributions to this study. In addition, the assistance provided by Mrs Sue Levi and Mrs Eleanor Pearl of the Tourette Syndrome Association was invaluable. Finally, Joshua Jablons, Lori Marino and Elizabeth Shusman provided help in conducting the experiment.

\section{References}

${ }^{1}$ Tourette de la G. Etude sur une affection nerveuse caractérisée par de l'inco-ordination motrice accompagné d'écholalie et de copralalie. Arch Neurol 1885;9:19-42, 158-200.

2 Shapiro AK, Shapiro ES, Bruun RD, Sweet RF. Gilles de la Tourette Syndrome. New York: Raven Press, 1978. 
${ }^{3}$ Moldofsky H, Tulles C, Lamon R. Multiple tic syndrome (Gilles de la Tourette Syndrome): Clinical, biological and psychosocial variables and their influence with Haloperidol. J Nerv Ment Dis 1974;159:282-9.

${ }^{4}$ Cohen DJ, Shaywitz BA, Young G, et al. Central biogenic amine metabolism in children and the syndrome of chronic multiple tics of Gilles de la Tourette. J Am Acad Child Psychiatry 1979;18:320-41.

${ }^{s}$ Nee LE, Caine ED, Polinsky RJ, Eldridge R, Ebert MH. Gilles de la Tourette Syndrome: clinical and family study of 50 cases. Ann Neurol 1980; 7:41-9.

- Clark DF. Behaviour therapy of Gilles de la Tourette's Syndrome. Br J Psychiatry 1966;112:771-8.

${ }^{7}$ Moldofsky H. A psychophysiological study of multiple tics. Arch Gen Psychiatry 1971;25:79-87.

${ }^{8}$ Cohen DJ. Comments in "Colloquium on Trauma." Int J Psychoanalysis 1978;54:365-75.

" Turpin G. The behavioural management of tic disorders: a critical review. Adv Behavior Res Ther 1983;5:203-45.

${ }^{10}$ Turpin G, Powell GE. Effects of massed practice and cue-controlled relaxation on tic frequency in Gilles de la Tourette's Syndrome. Behav Res Therap 1984;2: 165-78.

"Eysenck HJ. The Biological Basis of Personality. Springfield: Thomas, 1967.

12 Malmo RB. On Emotions, Needs and Our Archaic Brains. New York: Holt Rinehart Winston, 1975.

${ }^{13}$ Lacey JI. Somatic response patterning and stress: some revisions of activation theory. In: Appley MH, Trumbull R, eds. Psychological Stress: Issues in Research. New York: Meredith Publishing Co, 1967.

${ }^{14}$ Levy EZ, Thaler VH, Ruff GE. New techniques for recording skin resistance changes. Science 1958;128:33-4.

is Goldberger L. Physiological arousal, personality correlates and reactions to perceptual isolation. The XVIII International Congress of Psychology Moscow, Vol 1. Moscow. HAYKA, 1966.

${ }^{16}$ Raskin DC. Attention and arousal. In: Prokasy WF, Raskin DC, eds. Electrodermal activity in psychological research. New York: Academic Press, 1973.

${ }^{17}$ Israel NR. Perceptual assimilation: A study of the orienting reflex and the leveling-sharpening cognitive control principle. Dissertations Abstracts International 1966;67:6032.

${ }^{18}$ Hasset J. A Primer of Psychophysiology. San Francisco: WH Freeman, 1978.

${ }^{19}$ Rosvald HE, Mirsky AF, Sarason I, Bransome ED, Beck LH. A continuous performance test of brain damage. J Consult Psychol 1956;20:343-50.

${ }^{20}$ Mirsky AF, Kornetsky C. On the dissimilar effects of drugs on the digit symbol substitution and continuous performance tests. Psychopharmacologia 1964; 59:161-77.

${ }^{21}$ Orzak MH, Kornetsky G. Attention dysfunction in chronic schizophrenia. Arch Gen Psychiatry $1966 ; 14: 323-36$.

${ }^{22}$ Wohlberg GW, Kornetsky L. Sustained attention in remitted schizophrenics. Arch General Psychiatry 1973;28:533-7.

${ }^{23}$ Kornetsky L, Orzak MH. Physiological and behavioral correlates of attention dysfunction in schizophrenic patients. J Psychiatric Res 1978;14:68-79.

${ }^{24}$ Klein GS. Semantic power measured through the interference of words with color-naming. Am J Psychol 1964;78: 576-88.

${ }^{25}$ Calloway E. The influence of amobarbitol (amylobarbitone) and methamphetammine on the focus of attention. J Ment Sci 1959; 105:382-92.

${ }^{26}$ Hartley LR, Adams PG. Effects of noise on the Stroop test. J Exp Psychol 1974;102:62-6.

${ }^{27}$ Pellak MS, Pittman TS, Heller JP, Munson P. The effect of arousal on Stroop color-word task performance. Bull Psychonomic Soc 1975;6:248-50.

${ }^{28}$ Hochman SH. The effects of stress on Stroop color-word performance. Psychonomic Sci 1976;9:475-6.

${ }^{29}$ Wolitzky DL. Competing reaction tendencies: The effects of temporal sequence in inhibition and facilitation of response. Int Congress Psychol Proc 1966;3: 113.

${ }^{30}$ Zahn TP, Rosenthal D, Lawler WG. Electrodermal and heart rate orienting reactions in chronic schizophrenia. J Psychiatric Res 1968;66:117-34.

${ }^{31}$ Bernal ME, Miller HN. Electrodermal and cardiac response of schizophrenic children to sensory stimuli. Psychophysiology 1975; 7:155-68.

${ }^{32}$ Venables PH, Christie MJ. Electrodermal activity. In: Martin I, Venables PH, eds. Techniques in Psychophysiology. New York: John Wiley Sons, 1980.

${ }^{33}$ Edelberg R. Electrical activity of the skin, its measurement and uses in psychophysiology. In: Greenfield NS, Sternback SA, eds. Handbook of Psychophysiology. New York: Holt Rinehart Winston, 1972.

${ }^{34}$ Lader MH, Wing L. Habituation of G.S.R. in patients with anxiety states and in normal subjects. $J$ Neurology, Neurosurg Psychiatry 1964;27:210-8.

${ }^{35}$ Sadler TG, Mefford RB, Houch RL. The interaction of extraversion and neuroticism in orienting response habituation. Psychophysiology 1971;8:312-8.

${ }^{36}$ Lykken DT, Venables PH. Direct measurement of skin conductance response: A proposal for standardization. Psychophysiology 1971;8:656-72.

${ }^{37}$ Bull R, Gale A. Does the law of initial value apply to the galvanic skin response? Biol Psychol 1974;1:213-27.

${ }^{38}$ Johnson LC, Lubin A. On planning psychophysiological experiments: Design, measurement and analysis. In: Greenfield NS, Sternbach RA, eds. Handbook of Psychophysiology. New York: Holt Rinehart Winston, 1972.

${ }^{34}$ Lacey JI. The evaluation of autonomic responses: towards a general solution. Ann NY Acad Sci 1956;67: 123-64.

${ }^{40}$ Cohen J, Cohen P. Applied Multiple Regression/ Correlation Analysis for the Behavioral Sciences. Hillsdale: Erlbaum, 1975.

${ }^{41}$ Levine H. Robust tests for equality of variances. In: Okin I, ed. Contributions to Probability in Statistics. Stanford CA: Stanford University Press, 1960.

${ }^{42}$ Keppel G. Design and Analysis: A Researcher's Handbook. Englewood: Prentice Hall, 1973.

${ }^{43}$ Krumholz A, Singer H, Burnite R, Niedermeyer E. Electrophysiologic studies in the Tourette syndrome. First International Gilles de la Tourette Syndrome Sym- 
posium (Abstracts). New York NY: 1981.

${ }^{44}$ Sokolov EN. Neuronal Mechanisms of the Orienting Reflex. Hillsdale: Erlbaum Associates (distributed by Wiley), 1975.

${ }^{45}$ Mendelson WB, Caine ED, Goyer P, Ebert M, Gillin JC. Sleep in Gilles de la Tourette syndrome. Biol Psychiatry 1980;15:339-43.
${ }^{46}$ Glaze DG, Jankovic J, Frost Jr JD. Sleep in Gilles de la Tourette Syndrome: Disorder of Arousal. Neurology (NY) 1982;32: A153.

${ }^{47}$ Benditsky H. A psychosomatic approach to Gilles de la Tourette's Syndrome. Unpublished doctoral dissertation, Yeshiva University, 1978. 